\title{
Destrucción de la metafísica I, El punto de vista lógico y el problema de la universalidad. Cuestiones sobre la Isagoge de Porfirio y sobre la Metafísica de Aristóteles
}

\author{
JuAn Duns Escoto. \\ Introducción, traducción y notas de Carlos Mateo Martínez Ruiz (2019). \\ Villa María: Eduvim. 156 pp. ISBN: 978-987-699-605-1
}

\section{(1)}

\section{Valeria Buffon}

Universidad Nacional del Litoral / CONICET, Argentina

Uno de los grandes problemas que atraviesan la Edad Media es la llamada "cuestión de los universales". Uno de los más grandes pensadores de la Edad Media es Duns Escoto, el llamado Doctor Sutil. Estos dos datos asegurarían un bestseller a cualquier libro sobre este tema. Sin embargo, las obras de lógica de Duns Escoto, tal como lo relata Martínez Ruiz, solo han recibido la atención merecida muy recientemente. En esta ocasión el profesor de la Universidad Nacional de Córdoba hace disponible por primera vez en lengua castellana la discusión de Juan Duns Escoto sobre este milenario problema, y no tenemos más que agradecerle este gesto y esperar que otros lo sigan. De hecho, los especialistas de filosofía medieval tenemos el continuo problema de carecer de traducciones para el análisis pormenorizado, discusión de algunas tesis y para la enseñanza universitaria. Por lo tanto, siempre es una alegría recibir noticias sobre nuevas y buenas traducciones de textos filosóficos medievales.

Martínez Ruiz hace una introducción al autor muy completa y una contextualización de los textos presentados en traducción castellana, a saber, una selección de las Cuestiones sobre la Isagoge de Porfirio y sobre la Metafísica de Aristóteles (se trata de comentarios en forma de cuestiones). Cabe mencionar que ambas son obras de juventud, aunque las Cuestiones sobre la Metafísica serán revisadas continuamente hasta su muerte. Según Martínez Ruiz, por la forma de su organización las Quaestiones super de Escoto constituyen en sí un nuevo género que, si bien deriva de las cuestiones escolásticas desarrolladas en la universidad, tienen una complejidad más marcada, particular del franciscano. Curiosamente, los tratados de Parva logicalia de Escoto recién retomaron interés en la comunidad filosófica hacia fines del siglo XXI, quizás impulsados por los desarrollos de la filosofía analítica.

Tras una breve reseña de la vida y obras del doctor Sutil, Martínez Ruiz concluye que "a pesar de su juventud (o gracias a ella), el entonces bachiller escocés logra sistematizar una presentación analítica de su propia visión de la teología y de la ética, en el curso de la cual revisa y ajusta notablemente su concepción de la lógica, de la teoría del conocimiento y hasta su metafilosofía. Esta primera presentación sistemática de su pensamiento depende de una revisión profunda de la lógica y de la metafísica aristotélica, que quedó plasmada en una semántica modal completa, a saber, una teoría intensional de la modalidad (possibilitas logica), y en una metafísica de la contingencia sincrónica: las dos caras del mismo núcleo de una refundación de la filosofía. A ella le sumará el desarrollo completo de la tesis sobre la univocidad del concepto de ente" (p. 18).

De las Cuestiones sobre la Isagoge de Porfirio, son las doce primeras las que están traducidas aquí, que tratan de la lógica en general (1-3) y de los universales en general (4-12):

1. ¿Es la lógica una ciencia?

2. ¿Es la lógica una ciencia común a todas las ciencias?

3. ¿El sujeto de la lógica es el silogismo?

4. ¿El universal es un ente?

5. ¿El universal es inteligible por sí mismo?

6. ¿El universal tiene propiedades?

7. ¿El universal es el objeto del libro de Porfirio?

8. ¿Universal' es unívoco a los cinco predicables?

9. ¿El universal es en una cosa o en el entendimiento?

10. ¿[El enunciado] 'hombre es universal' es verdadero? 
11. ¿Las proposiciones como 'hombre es universal' son proposiciones por sí mismas?

\section{2. ¿Los universales son solamente cinco?}

Entre los temas destacados por Martínez Ruiz se encuentran:

1. La predicación de las intenciones segundas, las cuales son el objeto de la lógica a través del estudio del silogismo, pero con una "intencionalidad segunda" (que Escoto toma de Avicena), ya que la universalidad que interesa al escocés es aquella que es propia de la segunda intencionalidad, y esta es la que define el ámbito de la lógica como ciencia (p. 32).

2. La relación entre predicación y universalidad: he aquí el marco teórico desde el cual Escoto aborda el tipo de universalidad y de comunidad del concepto de ente. Este problema adquiere una importancia creciente desde los Parva logicalia hasta las obras de la madurez, convirtiéndose en la principal objeción lógica a la tesis de la univocidad con la que el escocés -según sus colegas- terminará por "destruir" la metafísica (p. 36). Cabe destacar que en las cuestiones traducidas en este volumen, "Escoto llega a reconocer el problema, plantear todos sus términos y vislumbrar el único camino de solución posible, que comenzará a bosquejar recién en Lectura I, al observar que, si "ente" es un concepto unívoco pero no es un género, y que, en tanto tal, se predica in quid pero sin constituir una definición, el elenco de los predicables es incompleto o, más bien, insuficiente" (p. 41).

3. Finalmente, Martínez Ruiz destaca la relación entre universalidad e intencionalidad en las inconclusas Cuestiones sobre la Metafísica (1290-1308) y en las Observaciones sobre la Metafísica. En el caso de la primera, su intrincada historia redaccional afecta, al parecer, principalmente la estructura misma de las cuestiones que el traductor detalla minuciosamente. Al ser las QSMA una obra de continua reescritura, constituye una descripción íntegra de la universalidad que según Martínez Ruiz completa el análisis comenzado en los Parva Logicalia. Es importante notar que es en la QSMA VII.18 (Cuestiones sobre la Metafísica de Aristóteles, Libro VII, q. 18: Si el universal es algo en las cosas, traducida aquí), donde Escoto desarrolla su teoría de la naturaleza común basándose en la esencia en sí (también llamada indiferencia de la esencia) de Avicena y que no adquiere un carácter ni de universalidad ni de singularidad a menos que esté en la mente (universalidad intencional) o en las cosas (comunidad natural). Esto da lugar a una descripción completa de la universalidad, es decir que por "universal" podemos entender por un lado la intención segunda o, por otro lado, lo denominado por esa intención, es decir, una intención primera.

Como lo resume el especialista de la UNC, según Escoto la universalidad no es un modo de ser de las cosas (puesto que solo hay individuos), sino un modo de entender las cosas. Por eso la universalidad no puede interpretarse como "comunidad", la cual pertenece al ámbito de la naturaleza. En efecto, solo algo indiferente puede ser común, por eso la naturaleza común es anterior y exterior a la mente capaz de conocerla. Es algo en las cosas, pero no es una cosa más. Por eso mismo, señala Martínez Ruiz siguiendo a Olivier Boulnois, "Escoto no puede ser considerado realista". Lo que funda la semejanza y la posibilidad de clasificar mentalmente un grupo de individuos en géneros y especies, es una identidad formal instanciable. La universalidad es el resultado de una acción cognitiva mediante la cual, al abstraer esa forma inteligible del individuo en que la reconoce, convierte positivamente lo indeterminado en universal.

Una introducción erudita con copiosa bibliografía permite que el libro sea provechoso para el investigador, a la vez que la traducción y comentario lo hacen accesible a un público no especializado y dan la posibilidad de introducir en los cursos de grado a este filósofo y teólogo medieval tan agudo en su análisis de un problema tan complejo. La traducción es hecha a partir de las ediciones críticas como lo dictan las reglas del arte, e indica oportunamente cuando se aparta de la edición crítica por decisión propia o siguiendo a otros especialistas. Establece claramente los criterios que sigue en su traducción indicando la precisión y objetividad como los principales. Copiosas notas detallan desde aclaraciones respecto de términos traducidos, pasando por un gran elenco de textos fuentes y de textos contemporáneos a Escoto con los cuales él discute, hasta discusiones pormenorizadas de la literatura secundaria especializada. El volumen incluye asimismo una cronología de la biografía de Duns Escoto, exposiciones generales sobre la vida y el modo de trabajar de los profesores universitarios de la época. Es, en síntesis, un volumen altamente recomendable tanto para acompañar la introducción al problema de los universales en la Edad Media como para la profundización y análisis detallado de la posición del Doctor Sutil al respecto. 